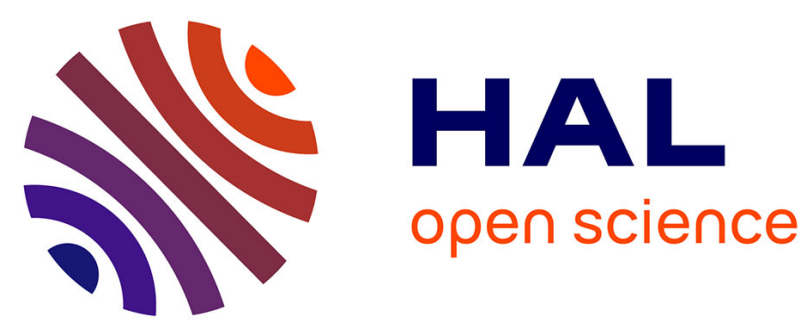

\title{
Legionella Effectors Explored with INSeq: New Functional Insights
}

Monica Rolando, Carmen Buchrieser

\section{To cite this version:}

Monica Rolando, Carmen Buchrieser. Legionella Effectors Explored with INSeq: New Functional Insights. Trends in Microbiology, 2018, 26 (3), pp.169-170. 10.1016/j.tim.2018.01.003 . pasteur02552011

\section{HAL Id: pasteur-02552011 https://hal-pasteur.archives-ouvertes.fr/pasteur-02552011}

Submitted on 16 Jun 2020

HAL is a multi-disciplinary open access archive for the deposit and dissemination of scientific research documents, whether they are published or not. The documents may come from teaching and research institutions in France or abroad, or from public or private research centers.
L'archive ouverte pluridisciplinaire HAL, est destinée au dépôt et à la diffusion de documents scientifiques de niveau recherche, publiés ou non, émanant des établissements d'enseignement et de recherche français ou étrangers, des laboratoires publics ou privés. 
2

3

4

5

6

7

8

9

10

11

12

13

14

15 16

17

18

19

20

21

22

23

24

25

26

27

28

29 *For correspondence:

30

31

32

33

34

\section{Keywords} factors

(2)

$$
1
$$

2
25

\section{6}

\section{Legionella effectors explored with INSeq: new functional insights}

Monica Rolando ${ }^{1,2}$ and Carmen Buchrieser ${ }^{1,2, *}$

${ }^{1}$ Institut Pasteur, Biologie des Bactéries Intracellulaires, Paris, France

${ }^{2}$ CNRS UMR 3525, Paris, France

Legionella pneumophila, bacterial effectors, transposon insertion sequencing, virulence 
35

36

37 Legionella pneumophila secretes over 300 effector proteins that manipulate host cells. This 38 multiplicity of effectors hampers the characterization of their individual roles. Shames et al.

39 report a new approach to solve the enigma of Legionella effector function by using INSeq to 40 analyse effector functions in the context of infection.
41

42

43

44 
Understanding how bacterial pathogens modulate host pathways and hence counteract host defence and cause disease is fundamental in our fight against infectious diseases. The intracellular pathogen Legionella pneumophila, the causative agent of Legionnaires' disease, is a unique model to study pathogen manipulation of host pathways during infection, with its sophisticated arsenal of molecular weapons that are secreted into the host cell to counteract host defences.

L. pneumophila is primarily an environmental bacterium that replicates within protozoan hosts (amoeba). When Legionella-contaminated aerosols are inhaled the bacterium can replicate within alveolar macrophages and cause an atypical pneumonia in susceptible individuals. L. pneumophila utilizes the same processes to parasitize human or protozoan cells as the L. pneumophila life cycle has been shown to be identical in all host cell types examined: the bacterium is internalized in a membrane-bound compartment called the Legionella containing vacuole (LCV) that escapes from lysosomal degradation, with the LCV remodeled through recruitment of host endoplasmic reticulum-derived vesicles into a protective vacuole for bacterial replication [1].

All key steps of the establishment of the LCV and the ability to replicate intracellularly are dependent on a functional Dot/Icm type IV secretion system (T4SS). This highly conserved machinery is essential for virulence as it secretes over 300 effector proteins into the host cell [2]. Genome sequencing has revealed a considerable plasticity and diversity in the effector repertoires encoded by different $L$. pneumophila strains, suggesting that this diversity allows adaptation to the different hosts L. pneumophila can parasitize [3]. Uniquely, among the over 300 T4SS effectors are an abundance of proteins with high similarity to eukaryotic proteins or proteins encoding eukaryotic-like domains, suggesting that molecular mimicry of eukaryotic proteins is a main virulence strategy of L. pneumophila [4]. Thus, the broad spectrum of tools employed for bacterial survival and replication in eukaryotic cells seems to have evolved during co-evolution of L. pneumophila and its protozoan hosts by horizontal gene transfer among domains of life, allowing this bacterium to parasitize a wide variety of hosts.

Although the T4SS is strictly necessary to initiate and sustain intracellular replication of L. pneumophila, the contribution of individual effectors remains minor [5]. Indeed, after the first excitement of scientists that L. pneumophila may encode as many functions as effectors, it soon became evident that high functional redundancy was present, and that most 
Furthermore, although a few effectors analyzed individually have been shown to play a role in intracellular replication of L. pneumophila, an efficient method to systematically assess the contribution of each effector was missing.

Shames and colleagues recently developed a new approach to define the contribution of the many L. pneumophila effector proteins during infection using a high-throughput transposon insertion sequencing technique called INSeq [6]. Guided by the principle of signature tagged mutagenesis, a number of groups have previously developed multiplex screening systems that combined random transposon mutagenesis and next generation sequencing (TnSeq) [7]. These comprehensive approaches allow high-resolution functional screening of whole genomes to identify key genes across various conditions in vitro or during host colonization. However, a limitation of in vivo experiments is that during the establishment of infection a considerable number of bacteria can be killed or removed stochastically; thus one cannot distinguish whether the bacteria were eliminated by chance or because they were indeed less fit. The approach of Shames et al. to circumvent such bottlenecks was to reduce the complexity of the input pool, establishing an effector mutant pool (EMP) library where 297 of the 315 genes predicted to encode effector proteins were represented. Subsequently they used the INseq technique to study the effects of this EMP on virulence phenotypes in amoeba, bone marrow-derived macrophages (BMDMs), and mice. This comprehensive approach allowed them to cluster individual mutants in distinct categories depending on their fitness phenotype. Mutants showing a universal defect, a mammalian-, lung-, BMDM-, or amoeba-specific virulence defect were identified. Indeed, effectors already known to play a role in L. pneumophila virulence were selected (e.g. mavN [8]), confirming the power of the technique to identify proteins implicated in virulence. Moreover, virulence phenotypes were detected for a large number of uncharacterized effector mutants, opening new vistas on the characterization of secreted L. pneumophila proteins. Due to the unbiased approach, effector proteins that contributed both positively and negatively to bacterial fitness could also be identified.

Another strength of the study was that the effector mutants were analyzed in three different host systems, which opened the possibility of evaluating the contribution of individual effectors in specific host contexts. An example is LegC4, an effector that, when deleted, conferred a competitive advantage on the mutant during in vivo murine infections, but not for ex vivo cellular infections. This was likely due to a role of $\mathrm{LegC} 4$ in stimulating pro-inflammatory responses in vivo that drive enhanced host control of the infection. 
Furthermore, new metaeffectors were identified. First described by Kubori and

113 colleagues [9], metaffectors are defined as effectors that act on another effector to modulate 114 its function in the host cell. The characterization of metaeffectors is an important step in 115 understanding L. pneumophila-host interactions as uncovering their spatiotemporal regulation 116 provides insight on how the bacterium modulates diverse host cell functions at discrete stages 117 of infection. Shames and colleagues showed that $\operatorname{Lpg} 2505$ is a metaeffector that regulates the 118 previously characterized effector SidI [10]. Interestingly, as with all metaeffectors identified 119 to date, $\operatorname{lpg} 2505$ constitutes an operon with sidI, and suppresses SidI toxicity to prevent host 120 damage that would limit L. pneumophila replication efficiency.

121 In summary, INSeq analyses of a defined effector mutant pool in three different 122 infection models allowed virulence phenotypes to be assigned to multiple effectors for which 123 functions were previously unknown. Furthermore, effectors having distinct impact in different 124 host models, or metaeffectors and effectors that act negatively on fitness can be identified. 125 This new approach to identifying previously cryptic effector functions can now be applied 126 across multiple bacterial pathogens and infection systems, opening the door to systematic 127 deconvolution of host-pathogen interactions. 
1. Isberg, R.R. et al. (2009) The Legionella pneumophila replication vacuole: making a cosy niche inside host cells. Nat Rev Microbiol 7 (1), 13-24.

2. Ensminger, A.W. (2016) Legionella pneumophila, armed to the hilt: justifying the largest arsenal of effectors in the bacterial world. Curr Opin Microbiol 29, 74-80.

3. Gomez-Valero, L. and Buchrieser, C. (2013) Genome dynamics in Legionella: the basis of versatility and adaptation to intracellular replication. Cold Spring Harb Perspect Med 3 (6), a009993.

4. Cazalet, C. et al. (2004) Evidence in the Legionella pneumophila genome for exploitation of host cell functions and high genome plasticity. Nat Genet 36 (11), 1165-1173.

5. O'Connor, T.J. et al. (2011) Minimization of the Legionella pneumophila genome reveals chromosomal regions involved in host range expansion. Proc Natl Acad Sci U S A 108 (36), 14733-40.

6. Shames, S.R. et al. (2017) Multiple Legionella pneumophila effector virulence phenotypes revealed through high-throughput analysis of targeted mutant libraries. Proc Natl Acad Sci U S A 114 (48), E10446-E10454.

7. van Opijnen, T. and Camilli, A. (2013) Transposon insertion sequencing: a new tool for systems-level analysis of microorganisms. Nat Rev Microbiol 11 (7), 435-442.

8. Portier, E. et al. (2015) IroT/mavN, a new iron-regulated gene involved in Legionella pneumophila virulence against amoebae and macrophages. Environ Microbiol 17 (4), 1338-50.

9. Kubori, T. et al. (2010) Legionella metaeffector exploits host proteasome to temporally regulate cognate effector. PLoS Pathog 6 (12), e1001216.

10. Shen, X. et al. (2009) Targeting eEF1A by a Legionella pneumophila effector leads to inhibition of protein synthesis and induction of host stress response. Cell Microbiol 11 (6), 911-926. 